\title{
Male involvement in antenatal and natal care practices of their partners - a community-based study in rural area of North Karnataka
}

\author{
Sarvar R. ${ }^{1}$, Sonavane R. ${ }^{2 *}$
}

DOI: https://doi.org/10.17511/ijphr.2018.i2.07

\footnotetext{
${ }^{1}$ Rana Sarvar, Assistant Professor, Karnataka Institute of Medical Sciences, Hubli, Karnataka, India.

2* Rekha Sonavane, Professor, Department of Community Medicine, Gadag Institute of Medical Sciences, Malasamudra, Karnataka, India.
}

Introduction: Male involvement, an all-encompassing term which refers to the various ways in which men relate to reproductive health problems and programmes, reproductive rights and reproductive behaviour. Objective: To assess the level of male involvement in the antenatal and natal care practices of women residing in Gadag. Methodology: A cross sectional study conducted in rural areas of Gadag. 100 Male partners of parous women formed the study group. They were interviewed regarding the reproductive profile of their partners and their level of knowledge and involvement in the Antenatal and natal health care utilisation. Perceptions regarding male involvement in reproductive health were also assessed. Results: $81 \%$ male partner accompanied their wives for at least one antenatal visit. Only $41 \%$ were aware of the complications which can occur during pregnancy, anemia being the most commonly known complication. 50\% confessed that they could not spend quality time with their partners during pregnancy due to work and other restrictions. With reference to the autonomy regarding decision making about vital events, the participants were given freedom only about the age of their marriage. Other decisions regarding use of family planning, antenatal care, newborn care, immunisation of child was taken by the elders in the family. Traditional male roles were cited as the most common reason for low male participation. Conclusion: In addition to the benefits for women and children, male involvement has potential benefits for men. Thus, programmes should be implemented based on the understanding of gender dynamics, on how decisions are made and implemented, on the changing needs of both genders and their interaction.

Keywords: Male involvement, Maternal and child health care, Birth preparedness, Barriers to male involvement

\section{Corresponding Author}

Rekha Sonavane, Professor, Department of Community Medicine, Gadag Institute of Medical Sciences, Malasamudra, Karnataka, India. Email: drrekha.sonavane@gmail.com
How to Cite this Article

To Browse

Sarvar R, Sonavane R. Male involvement in antenatal and natal care practices of their partners - a community-based study in rural area of North Karnataka. Public Health Rev Int J Public Health Res. 2018;5(2):92-98.

Available From

https://publichealth.medresearch.in/index.php/ijphr/ article/view/88

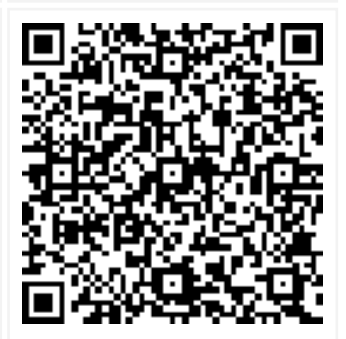

Manuscript Received 2018-05-28

Conflict of Interest No
Review Round 1 2018-06-07

Funding

Nil

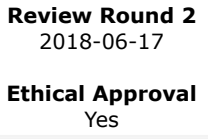

Review Round 3

Plagiarism X-checker $9 \%$
Accepted 2018-06-19

(C) 2018 by Rana Sarvar, Rekha Sonavane and Published by Siddharth Health Research and Social Welfare Society. This is an Open Access article licensed under a Creative Commons Attribution 4.0 International License https://creativecommons.org/licenses/by/4.0/ unported [CC BY 4.0]. 


\section{Introduction}

In many parts of India child birth is supposed to be asolely woman's issue. Here males enjoy more social andeconomic power, especially in the rural areas, where male partner takes control over his female partner. Male partner decides family size, what type of healthcare services will their spouse avail during pregnancy and in some cases timingof pregnancy too. However male partner usually staysalo of after she conceives.

As a result the pregnancy related complications are not noticed in time there by increasing the risk of maternal mortality. In this situation when India is still trying to reduce maternal mortality rate (MMR), male involvement in antenatal care could be a key to success as it will enable them tosupport their spouses for adequate preparation for birthand to utilize emergency obstetric care early ifcomplications arise. There by having a positive impact on birth outcomes [1]. The 1994 International Conference on Population Development in Cairo was among the first international declarations which highlighted the importance of involvement of men in reproductive health programs. It recognised men's impact on women's reproductive health through their role as partners, fathers and healthcare workers. These effects can be direct and indirect, biological and social [2].

Women bear many health burdens, such as childbearing, fertility regulation and associated contraceptive side-effects, and recourse to abortion as a consequence of non-use of contraceptives or method failure. Thus, married women of reproductive age (MWRA) have been the primary focus of reproductive health research and programme interventions. In the past, programmes had focused on demographic and target-oriented objectives with very little emphasis on quality issues. Programmes have also failed to address the relations among men and women and their responsibilities [3].

But it is time to realise that Utilization of maternal health care depends not only on the availability of services but also on different other factors such as distance of health care facility; perception of women and husband and their families regarding the need for care; social restrictions on freedom to movement; the opportunity cost of accessing health care; and the interaction between the client and the provider of formal health care system.
Also, as a woman's social status and her health are intrinsically related, her low status often is the cause of poor access to essential [4].

Even today, tradition, norms and values govern Indian social behaviour. Reproductive and child health are personal matters to an Indian woman. Males are less involved in it, though they wield more authority in the domain of women's health care decisions. Even within the house hold, women have restricted roles: cooking, taking care of the family and rearing children.

Thus, women's involvement in maternal health in a patriarchal society like India is a big challenge. Until male partners are mobilized to participate in reproductive health care and encourage women to avail themselves of health care facilities during and after pregnancy, achieving high coverage of antenatal care or safe delivery by skilled birth personnel, as stated in Goal 5 of the Millennium Development Goals (MDGs), will remain a day dream [5].

These reasons illustrate the urgency of the need to include men in $\mathrm{MCH}$ and $\mathrm{RCH}$ care. Male involvement, an all-encompassing term which refers to the various ways in which men relate to reproductive health problems and programmes, reproductive rights and reproductive behaviour. In this study we aim to assess the level of male involvement in the antenatal and natal care practices of womenresiding in Gadag.

\section{Methodology}

This is a cross sectional community-based study conducted in rural areas of Gadagtaluk. Male partners of parous women formed the study group. All married men with children were included. Men who did not consent or those who were not with their wives during her pregnancy due to work or other reasons were excluded. Sample size was calculated using male involvement for antenatal care as $42 \%$ for India (IIPS) and $7 \%$ error and $95 \%$ confidence interval [5].

100 male partners were enrolled using convenient sampling and were interviewed using a pretested semi-structured questionnaire. They were interviewed regarding the reproductive profile of their partners and their level of knowledge and involvement in the Antenatal and natal health care utilisation after their informed consent. Perceptions regarding male involvement in reproductive health were also assessed. 
Three broad categories were considered as indicating male involvement:

- Active participation in maternal health services and care (husband's attendance of antenatal care (ANC); husband's presence at delivery room; and husband's support/help to wife during pregnancy, delivery or at post partum);

- Financial support given for pregnancy-related and childbirth-related expenses;

- Decision-making power on maternal health.

The data was entered into MS excel and analyzed using SPSS using chisquare statistical tests.

\section{Results}

Our study included 100 male participants belonging to rural areas of Gadag taluk. 92 of which were Hindu and rest were Muslims. Majority of the participants had received education upto SSLC (27\%), 23\% were degree holders and $21 \%$ has passed PUC, 27\% passed 10th, 8\% 7th standard and 3 are illiterate. The socioeconomic class of majority $(73 \%)$ fall under class 3 and 4 as per modified B.G Prasad classification.

A predominant joint family system (64\%) was observed in the study area. The head of the family and the main decision-making authority being vested in the fathers of the participants. With reference to the autonomy regarding decision making about vital events, the participants were given freedom only about the age of their marriage.

Other decisions regarding use of family planning, antenatal care, newborn care, immunisation of child was taken by the elders in the family. The reproductive profile of the participants is as follows. $48 \%$ had 2 children and $33 \%$ had 1 child. $81 \%$ of them were born by normal vaginal route.

The birth weight of $8 \%$ children was below $2.5 \mathrm{~kg}$. With respect to antenatal care provided to their partners. $73 \%$ were registered within 3 months and only $61 \%$ had 4 or more antenatal visits. $81 \%$ male partner accompanied their wives for atleast one antenatal visit. Only $41 \%$ were aware of the complications which can occur during pregnancy, anemia being the most commonly known complication.
Regarding the care provided by the participants to their pregnant wives at home. $63 \%$ ensured that she got some rest and $77 \%$ of them even assisted her in domestic chores. $75 \%$ provided good nutrition and $82 \%$ felt they provided mental and emotional support to the pregnant wives. However, $50 \%$ confessed that they could not spend quality time with their partners during pregnancy due to work and other restrictions.

It was also found that 33\% consumed alcohol and $82 \%$ used tobacco products even during the pregnancy period and 35\% reported to have domestic quarrels with their wives during the antenatal period.

Majority of the male partners had involved in birth preparedness. $93 \%$ of them had pre-arranged finances for delivery but transportation was arranged after the onset of labour pains by $86 \%$ participants. $87 \%$ participants were physically present at the time of their wives delivery but only $68 \%$ spent quality time with their postnatal wives and newborns.

$91 \%$ males agree that postnatal care is important for restoration of women's health (53\% less than 3 months 41\% 3-6 months and $6 \%$ more than 6 months). Although $95 \%$ feel a postnatal visit to the hospital is necessary, it is seldom practiced.

Regarding the male partners' role in providing finance, emotional support and help in child care to the postnatal wife, only 35\% acknowledge they have equal responsibility. $20 \%$ feel that theirs is a supportive role and $38 \%$ feel it's the wife's parents' responsibility and $7 \%$ out rightly claimed that they are not responsible for postnatal care.

Table No-1: Reasons for low male participation.

\begin{tabular}{|l|l|l|}
\hline \multicolumn{1}{|c|}{ Reasons for low male participation } & Frequency & Percent \\
\hline Traditional male role & 61 & 61 \\
\hline Lack of knowledge & 20 & 20 \\
\hline Previous negative experiences in health care places & 7 & 7 \\
\hline Busy with earning livelihood & 10 & 10 \\
\hline Perceived low accessibility to join ANC visits & 2 & 2 \\
\hline
\end{tabular}


Table No-2: Decision making authority vs educational profile of participants.

\begin{tabular}{|c|c|c|c|c|c|c|c|}
\hline \multicolumn{2}{|c|}{ Decision making authority in participants } & \multicolumn{5}{|c|}{ Educational profile of participants } & \multirow[t]{2}{*}{ P value } \\
\hline & & Below 7th std & Up to10thstd & PUC & Degree & Total & \\
\hline \multirow[t]{2}{*}{ Timing of marriage } & Self decision & 16 & 18 & 9 & 10 & 53 & \multirow[t]{2}{*}{.286} \\
\hline & Elders decision & 13 & 9 & 12 & 13 & 47 & \\
\hline \multirow[t]{2}{*}{ Use of family planning } & Self decision & 5 & 14 & 12 & 3 & 34 & \multirow[t]{2}{*}{$0.001 *$} \\
\hline & Elders decision & 24 & 13 & 9 & 20 & 66 & \\
\hline \multirow[t]{2}{*}{ Utilisation of antenatal care } & Self decision & 8 & 15 & 16 & 10 & 49 & \multirow[t]{2}{*}{$0.006 *$} \\
\hline & Elders decision & 21 & 12 & 5 & 13 & 51 & \\
\hline \multirow[t]{2}{*}{ Newborn care practices } & Self decision & 3 & 13 & 8 & 5 & 29 & \multirow[t]{2}{*}{$0.011 *$} \\
\hline & Elders decision & 26 & 14 & 13 & 18 & 71 & \\
\hline \multirow[t]{2}{*}{ Immunisation of newborn } & Self decision & 5 & 12 & 14 & 4 & 35 & \multirow[t]{2}{*}{$0.001 *$} \\
\hline & Elders decision & 24 & 15 & 7 & 19 & 65 & \\
\hline
\end{tabular}

Table No- 3: Participation in ANC and delivery care vs financial contribution of participants.

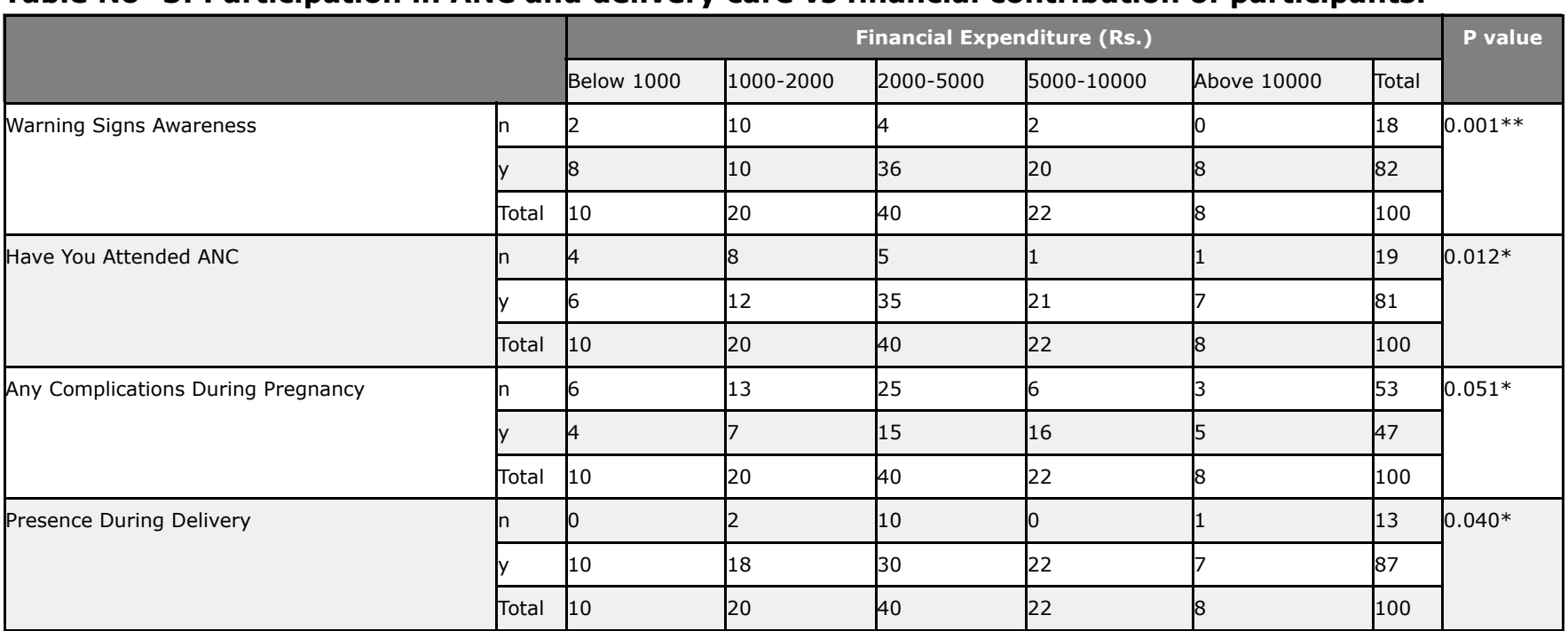

Thus only $38 \%$ male participants felt that they had provided good care to their partners during and after her pregnancy while $22 \%$ felt that their role was limited due to work and other obligations and $40 \%$ reported that they have not sufficiently involved with maternal and child care. Regarding the scope for greater involvement of men in reproductive matters, $89 \%$ supported the idea and the reasons cited for low involvement are given in the table. On analysis it was found that a statistically significant proportion of men attended the antenatal visits only if their wives had/ developed some complications $(p<0.001)$. Financial contribution of the male partner during pregnancy was also found to be an important determinant of male involvement in $\mathrm{MCH}$ care.

\section{Discussion}

Our study focuses on involvement of the male in reproductive health of their partner's around child birth.
It was thus found that role of men is limited mainly due to the patriarchal norms of the society where men are responsible only for earning and other matters are decided by the elders in our family. As most of our participants were from joint families this fact is clearly demonstrated.

However male involvement is associated with better health outcomes and utilisation of health services. This finding is supported by other studies.

Kumar Chiman examines the association between the men's knowledge regarding the maternal health service utilization and maternal health in India using data from National Family Health Survey 2005-06.

The indicator of maternal health used in the analysis was safe delivery. He concludes that husband can significantly influence the women's health care utilization. In all India level and in state level some factors which determine the women's ANC visit and decide the place of delivery are same. 
Education, age, place of residence, number of living children, caste, religion are some of the major factors which reduce husbands presence at the time of ANC visit and also restrict women into the house hold and leads non institutional delivery. Presence of violence decreases the husbands' presence at the time of wives ANC visit but increase the institutional delivery.

His findings clearly suggest that male involvement and their knowledge about maternal health significantly associated with the maternal health. Those women whose husband have knowledge regarding maternal health and are present at the time of ANC visit more likely to utilize safe delivery service [4]. This agrees with our study.

Aparajita Chattopadhyay conducted a study that aims to look into the variations and determinants of maternal health care utilization in India and in three demographically and socioeconomically disparate states, namely Uttar Pradesh, West Bengal and Maharashtra, by husband's knowledge, attitude, behaviour towards maternal health care and gender violence, using data from the National Family Health Survey III 2005-06.

She found that Men's knowledge about pregnancyrelated care and a positive gender attitude enhances maternal health care utilization and women's decision-making about their health care, while their presence during antenatal care visits markedly increases the chances of women's delivery in institutions.

Hence the study recommended that from a policy perspective, proper dissemination of knowledge about maternal health care among husbands and making the husband's presence obligatory during antenatal care visits will help primary health care units secure better male involvement in maternal health care [5].

A systematic review and meta-analysis was undertaken by Yargawa J, et al.to consider the impact of male involvement on maternal health outcomes in developing countries. This review has demonstrated statistically significant beneficial impacts of male involvement on maternal health through reduced odds of maternal depression and improved utilisation of maternal health services (relating to SBA and postnatal care). Male involvement was also associated with decreased likelihood of childbirth complications, although results showed contradictory significance.
There was little evidence of beneficial maternal health outcomes from husbands' presence in the delivery room. Further more, the synthesis of evidence suggests that male involvement during pregnancy and at post partum appear to offer statistically significant maternal health benefit than male involvement during delivery [6].

Previous studies have linked husbands' attendance of ANC with increased maternal health service utilisation. A possible explanation for this association is that men's knowledge about the importance of maternal health services increases with active participation, which in turn makes them more likely to encourage and support their wives to use them.

In a developing country setting, this acquired knowledge could also translate into the husbands' grant of permission and provision of resources for accessing maternal services such as transportation to hospital for delivery, payment of user fees and so on [6-11].

It has been reported in literature that men's offer of practical support can reduce women's workload during pregnancy and ensure they rest sufficiently, therefore one could hypothesise that this offer of practical support could translate through pregnancy to childbirth, where the risk of complications may be minimised. In addition, male involvement fosters adequate complication readiness and birth preparation in the form of recognising danger signs and making arrangement for SBA among other things.

This in turn prevents delays in accessing care, decreases risk of developing complications and also averts maternal mortality. In the Indonesian Suami SIAGA ('alert husband') campaign, men exposed to the programme were 1.7 times more likely than unexposed men to take alert actions against birth complications $(p<0.001), 67$ there by reducing women's likelihood of experiencing them $[6,12,13]$.

Our finding reinforces other studies showing that women were more likely to have better outcomes when their husbands got directly involved in maternal health care by attending ANC visits and supported their wives during pregnancy. Studies in South Asia have found that women whose husbands show concern in pregnancy are more likely to utilize reproductive health services.

Further, some studies have shown that, when men know the danger signsof pregnancy and delivery, 
They may act as life-saving agents, ensuring that their wives get appropriate attention in obstetric emergencies [14].

Kululanga et al. examines and describes through indepth interviews the strategies that were used by different health care facilities to invite husbands to participate in maternal health care in rural and urban settings of southern Malawi. Four main strategies were used to invite men to participate in maternal health care.

The strategies were; health care provider initiative, partner notification, couple initiative and community mobilization. The health care provider initiative and partner notification were at health facility level, while the couple initiative was at family level and community mobilization was at village (community) level.

The community mobilization had three sub-themes namely; male peer initiative, use of incentives and community sensitization. The study found that the couple strategy was most appropriate but was mostly used by educated and city residents. The male peer strategy was effective and sustainable at community level. There is need for creation of awareness in men so that they sustain their participation in maternal health care activities of their female partners even in the absence of incentives, coercion or invitation [15].

A randomised controlled trial conducted in Nepal by Mullany et al. to test the impact of involving male partners in antenatal health education on maternal health care utilization and birth preparedness in urban Nepal. In total, 442 women seeking antenatal services during second trimester of pregnancy were randomized into three groups: women who received education with their husbands, women who received education alone and women who received no education.

The education intervention consisted of two 35-min health education sessions. Women were followed until after delivery. They found that Women who received education with husbands were more likely to attend a post-partumvisit than women who received education alone $[R R 51.25,95 \%$ CI 5 $(1.01,1.54)$ ] or no education [RR $51.29,95 \%$ CI 5 $(1.04,1.60)]$.

Women who received education with their husbands were also nearly twice as likely as control group women to report making $>3$ birth preparations [RR 5 $1.99,95 \%$ CI $5(1.10,3.59)]$.
Study groups were similar with respect to attending the recommended number of antenatal care checkups, delivering in a health institution or having a skilled provider at birth.

These data provide evidence that educating pregnant women and their male partners yields a greater net impact on maternal health behaviours compared with educating impact of involving male partners in antenatal women alone [16].

\section{Conclusion}

Despite their frequent position as primary decision maker, men tend to be excluded from health services and spaces in which they could learn more about family planning, pregnancy and childbirth. The exclusion can be sociocultural, in that pregnancy and childbirth is often considered 'women's business', and it can be economicas men have to work away from home.

It can also be programmatic; an exclusive focus on women in maternal health programs may result in health services that areinaccessible to men. This exclusion may mean that men are less able to make informed decisions about reproductive and maternal health, and less willing to engage insuch decisionmaking with their partners.

There is sufficient evidence that ignorance, indifference and lack of concern on the part of men act as hindrances to fulfilling $\mathrm{MCH}$ goals. Household dynamics of power relations are critical in this respect. Empowering women and giving equal importance to men are necessary, along with proper dissemination of knowledge among men.

Thus men's support in every respect is a necessary prerequisite for sound maternal health care. As a good proportion of husbands accompany their wives to ANC check-ups and the husband's presence in ANC enhances the chances of institutional delivery, it could be made mandatory to counsel husbands along with their wives during ANC visits.

Level of knowledge received during wife's pregnancy by the husband is another vital determinant of ANC and safe delivery. There should be concerted action to step up efforts to educate men about reproductive and maternal health. Thus, programmes should be implemented based on the understanding of gender dynamics, on how decisions are made and implemented, on the changing needs of both genders and their interaction [17]. 


\section{Contribution from the authors}

Dr Sarvar prepared the study design and manuscript and Dr Sonavane contributed in the data collection.

\section{What this study adds?}

This study considers the perspectives of male counter-part in the reproductive life and highlights the constraints and concern faced by them. This insight can help in reorienting our health delivery system to be more need based and client oriented.

\section{Reference}

01. Obi AI, Abe E, Okojie OH. Male and Community Involvement in Birth Preparedness and Complication Readiness in Benin City, Southern Nigeria. IOSR J Dental Med Sci. 2013;10(6)2732.

[Crossref]

02. Dudgeon MR, Inhorn MC. Men's influences on women's reproductive health- medical anthropological perspectives. Soc Sci Med. 2004 Oct;59(7)1379-95.

DOI: 10.1016/j.socscimed.2003.11.035 [Crossref]

03. Ashraf Ali, Kane Thomas, Shahriar Ahsan, Barkat-e-Khuda. Male Involvement in Reproductive Health Services in Bangladesh- A Review. ICDDR, B- Centre for Health and Population Research Mohakhali, Dhaka 1212, Bangladesh 1999 ICDDR, B-Special Publication No-94.

[Crossref]

04. Kumar Chiman Sinha. Male involvement and utilization of maternal health services in India. International Journal of Scientific and Research Publications. 2014(nov); Vol-4, Issue 11.

[Crossref]

05. Chattopadhyay A. Men in maternal care: evidence from India. J Biosoc Sci. 2012 Mar;44(2)129-53.

doi: 10.1017/S0021932011000502. Epub 2011 Oct 18 [Crossref]

06. Yargawa J, Leonardi-Bee J. Male involvement and maternal health outcomes- systematic review and meta-analysis. BMJ. 2015.

doi: 10.1136/jech-2014-204784. Epub 2015 Feb 19 [Crossref]
07. Redshaw M, Henderson J. Fathers' engagement in pregnancy and childbirt- evidence from a national survey. BMC Pregnancy and Childbirth. 20 Mar;2013.

DOI: $10.1186 / 1471-2393-13-70$ [Crossref]

08. Tweheyo R, Konde-Lule J, Tumwesigye NM, Sekandi JN. Male partner attendance of skilled antenatal care in peri-urban Gulu district, Northern Uganda. BMC Pregnancy and Childbirth. 16 Sep;2010.

doi: $10.1186 / 1471-2393-10-53$ [Crossref]

09. Hossain M, Ahmed K, Bulbul T, et al. Human rabies in rural Bangladesh. Epidemiol Infect. 2012 Nov;140(11)1964-71.

DOI: $\quad 10.1017 /$ S095026881100272X [Crossref]

10. Ali M1, Rizwan $H$, Ushijima $H$. Men and reproductive health in rural Pakistan-the case for increased male participation. Eur J Contracept Reprod Health Care. 2004 Dec;9(4)260-6. [Crossref]

11. KakaireO, Kaye DK, Osinde MO. Male involve ment in birth preparedness and complication rea diness for emergency obstetric referrals in rural Uganda. Reproductive Health. 7 May; 2011. DOI: $10.1186 / 1742-4755-8-12$ [Crossref]

12. Bhatta DN. Involvement of males in antenatal care, birth preparedness, exclusive breast feeding and immunizations for children in Kathmandu, Nepal. BMC Pregnancy and Childbirth. 16 Jan;2013.

doi: 10.1186/1471-2393-13-14 [Crossref]

13. Shefner-Rogers $C L$, Sood S. Involving husbands in safe motherhood- effects of the SUAMI SIAGA campaign in Indonesia, In- Davis J, Luchters S, Holmes $W$; Men and maternal and newborn health- Benefits, harms, challenges and potential strategies for engaging men; 2012. J Health Commun. 2004;9;233-58.

[Crossref]

14. Mangeni JN, Mwangi A, Mbugua S, Muktar V. Male Involvement in Maternal Health Care as a Determinant of Utilization of Skilled Birth Attendants in Kenya. Demographic And Health Surveys, ICF International Calverton, Maryland, USA. 2013; No-93.

[Crossref] 
15. Kululanga LI, Sundby J, Malata A, Chirwa E. Striving to promote male involvement in maternal health care in rural and urban settings in Malawi - a qualitative study. Reproductive Health. 2 Dec; 2011.

doi: $10.1186 / 1742-4755-8-36$ [Crossref]

16. Mullany BC, Becker S, Hindin MJ. The impact of including husbands in antenatal health education services on maternal health practices in urban Nepal- results from a randomized controlled trial. Health Educ Res. 2007 Apr;22(2)166-76.

DOI: $10.1093 /$ her/cyl060 [Crossref]

17. Ampt F, Mon MM, Than KK, et al. Correlates of male involvement in maternal and newborn health- a cross-sectional study of men in a periurban region of Myanmar. BMC Pregnancy and Childbirth. 27 May;2015.

doi: $\quad 10.1186 / \mathrm{s} 12884-015-0561-9 \quad$ [Crossref] 